\title{
Cultura originaria y diálogo de saberes en el aprendizaje de la lengua Mapuzugun
}

\author{
OMAr TurRa Díaz \\ Universidad Católica de Temuco \\ Lila Moreno Rubio \\ Universidad San Sebastián \\ José HuenuPI MARILEO \\ Educador tradicional mapuche
}

Recibido: 16 diciembre 2013 / Aceptado: 17 noviembre 2014

ISSN: 1697-7467

\begin{abstract}
RESUMEN: El artículo expone el proceso y resultados de una experiencia educativa que tuvo como propósito fortalecer el habla de la lengua originaria mapuche en niños y niñas que asisten a los centros educativos preescolares localizados en la Región del Biobío, Chile. La propuesta educativa, entiende y promueve el aprendizaje de la lengua en estrecha relación con la cultura de referencia y, desde el diálogo de saberes educativos de los diversos agentes partícipes de la experiencia.

Los resultados evidencian un fortalecimiento en el dominio de la lengua indígena, además del acercamiento entre la comunidad originaria y los centros educativos.
\end{abstract}

Palabras clave: Mapuzugun, lengua y cultura indígena, diálogo de saberes.

\section{Originary Culture and Knowledge Dialogue in the Learning of Mapuzungun}

\begin{abstract}
The article shows the process and results of an educational experience that was aimed to strengthen speech of native Mapuche language in children attending preschool education centers in the Biobío Region, Chile. The educational proposal understands and promotes language learning in close connection with the reference culture and from the dialogue of educational knowledge of the various actor's participants of the experience. The results are showing a strengthening in the domain of the indigenous language in addition to bringing together the original community and schools.
\end{abstract}

Keywords: Mapuzugun, indigenous language and culture, knowledge dialogue.

\section{INTRODUCCIÓN}

Ante el preocupante diagnóstico que plantea un retroceso del habla de las lenguas originarias en Chile, es que desde la política pública en educación se vienen promoviendo programas y proyectos de intervención educativa orientados a revitalizar las lenguas indígenas a través del sistema escolar. Se trata de programas de Educación Intercultural Bilingüe, que han focalizado su intervención en la educación básica o primaria del país. 
Sin embargo, evaluaciones realizadas de las experiencias de educación intercultural han concluido que las escuelas adheridas a este programa incorporan los contenidos de las culturas originarias como una materia más del currículum nacional. Es decir, no se despliegan ni describen esfuerzos que digan relación con el rescate, valoración y uso de las formas de educar propios de la cultura originaria. En rigor, la enseñanza de la lengua originaria se integra al currículo de educación básica con un formato didáctico homologable a una asignatura de idioma extranjero.

Desde estos antecedentes, el presente artículo reporta una experiencia educativa que puede definirse como una propuesta de innovación pedagógica para la enseñanza de la lengua originaria, en tanto tuvo como objetivo central desarrollar estrategias y acciones participativas de carácter dialógico y comunitario para fortalecer la enseñanza y aprendizaje de la lengua mapuzugun de los niños y niñas que asisten a los jardines infantiles interculturales de la Región del Biobío. Actuaron como principios orientadores en el diseño de la propuesta, aquel conocimiento sociolingüístico que plantea que la mejor forma de mantener y proyectar una lengua es utilizándola en la primera etapa de adquisición lingüística de los niños y niñas (Teberosky y Soler, 2003, Martínez, 2004); y el conocimiento educativo que propone la participación activa de los miembros de la comunidad originaria en los procesos de fortalecimiento de la lengua indígena (Baronnet, 2013).

La propuesta pedagógica focalizó su trabajo en seis jardines infantiles mapuches, localizados en la Región del Biobío, Chile, en cuyos centros fueron integrados Educadores de la Lengua y Cultura Indígena (ELCI) quienes desarrollaron procesos de enseñanza de la lengua mapuche vinculados a sus formas culturales, tanto en los contenidos como en las funciones que ella cumple en el ámbito comunitario. La comunidad participó expresando sus intereses y expectativas para el diseño de la propuesta, fomentando el apoyo en el habla del mapuzugun desde los hogares, y con la presencia de miembros hablantes en actividades educativas de los jardines.

\section{Marco teórico}

El mapuzugun es una de las lenguas originarias con mayor número de hablantes en Chile, a pesar de su histórico retroceso producto de la imposición del castellano como lengua oficial. En la región de la Araucanía, territorio tradicional de asentamiento mapuche, según registros sociolingüísticos recientes, es donde se encuentra el mayor porcentaje de bilingüismo, por cuanto cerca de la mitad de la población de ascendencia mapuche posee algún tipo de dominio en la lengua originaria (Gundermann et al., 2008, Henríquez, 2014). Sin embargo, como se evidencia en otros estudios, esta situación sociolingüística presenta una notable heterogeneidad en el nivel de dominio de la lengua, asociada a variables como el territorio de que se trate, grupos etarios y de orden demográfico (ruralidad-urbanidad) (Gundermann et al., 2008, 2009, Wittig, 2009).

Como la generalidad de las lenguas originarias, el mapuzugun posee como característica esencial la oralidad, por lo que el componente verbal tiene una importancia primordial en la interrelación y en el intercambio o traspaso del contenido cultural (Catrileo, 2005). Actualmente, el mapuzugun continúa teniendo una tradición mayormente oral y el desarrollo de su escrituración es un proceso reciente que se asocia a los esfuerzos por revitalizarla y 
a disponer de recursos para enseñarla en el sistema escolar, puesto que se sabe que la gran mayoría de niños y niñas indígenas escasamente aprenden la lengua materna en sus hogares, inclusive en aquellos espacios tradicionales de asentamiento mapuche.

En este proceso de ruptura en las prácticas comunicativas o discontinuidad en el desarrollo lingüístico indígena, la escuela pública ha jugado un rol fundamental a través de su política de castellanización y asimilación cultural (Donoso, 2008; Turra, 2008-2009). Históricamente, la escuela chilena en la Araucanía ha recreado la cultura occidental y otorga carta de legitimidad a una única modalidad cultural (Quintriqueo, 2010). Se configura como una entidad educativa que niega el conocimiento mapuche (Quilaqueo et al., 2007) y promueve prejuicios hacia sus prácticas culturales (Quilaqueo y Merino, 2003).

En este ambiente educativo, los escolares indígenas perciben y refuerzan la idea que el mapuzugun tiene escasa importancia para sus interacciones diarias y utilizan el castellano como lengua base para su comunicación. Consecuencia de la escolarización es que, llegados a la vida adulta, los padres no muestran mayor interés en entregar algún conocimiento a sus hijos sobre la lengua y cultura de origen (Catrileo, 2005).

Desde la perspectiva de la relación entre la lengua oficial y las lenguas originarias, ella se puede conceptualizar como de desplazamiento lingüístico o de diglosia sustitutiva, en tanto se ha configurado una relación asimétrica entre una lengua dominante y otra dominada (Gundermann et al., 2009, Vergara y Gundermann, 2005). Ello se caracteriza por una creciente expansión de la lengua dominante lo que conlleva a un extremo desequilibrio y desigualdad, donde la lengua oficial tiene acceso a múltiples recursos y ventajas a los cuales no acceden las lenguas indígenas.

En este contexto, la inserción de la lengua originaria en el sistema escolar forma parte de una política estatal remedial que busca avanzar en contextualización curricular y en la afirmación identitaria del estudiantado indígena (Turra, 2012) y con ello contrarrestar el déficit en la autoestima de los niños indígenas, de manera que, superados estos problemas, sea posible exhibir mejores resultados en los procesos de enseñanza aprendizaje (AlvarezSantullano y Forno, 2008). Mejorar los resultados de aprendizaje del estudiantado mapuche, y hacerlo a partir de su cultura de referencia, significa replantear la estructura tradicional de la escuela y el desempeño docente en estos contextos, pues los escasos logros académicos evidencian una reproducción de la inequidad educativa desde las actuales prácticas y actuaciones pedagógicas. En efecto, los escolares indígenas son los que obtienen los menores rendimientos académicos en el sistema escolar chileno y presentan un mayor riesgo de fracaso escolar que los escolares no indígenas (McEwan, 2004).

Fortalecer el aprendizaje de la lengua originaria a través del sistema escolar implica pensar la escuela más allá de sus conformaciones tradicionales, de manera de dar cabida a sujetos y saberes por antonomasia ausentes en la estructura de lo escolar. Significa, partir del supuesto de la diversidad epistemológica del mundo y promover una ecología de los saberes, en palabras de Sousa Santos (2009), para así dar legitimidad al conocimiento indígena que rodea a la escuela, para que éste, junto al conocimiento académico, genere propuesta educativa. Esta línea de argumentación se encuentra en coherencia con aquella literatura investigativa en educación, que establece que el éxito de un proyecto de transformación educativa se asegura desde la construcción y acuerdo de la mayoría de los agentes educativos involucrados (Aubert et al., 2010) y, también con la investigación que viene proponiendo la necesidad de superar modelos pedagógicos tradicionales para avanzar hacia una pedagogía 
dialógica, que incorpore otros referentes sociales (colaboradores de aprendizajes) al interior de aula, de modo de superar la exclusividad del docente como referente de aprendizaje y ampliar con ello las oportunidades de aprendizaje para este tipo de alumnado (Ferrada y Flecha, 2008; Ferrada, 2012).

Por tanto, la construcción de comunidades educativas centradas en procesos participativos, otorgan potencialidad y proyección a una propuesta de revitalización de la lengua originaria en la medida que incorpora agentes educadores propios de la cultura, que hablen la lengua con fluidez y otorguen sentido cultural a las interacciones comunicativas. Para el caso mapuche se ha planteado la necesidad de contar con educadores tradicionales capaces de moverse en dos planos: la transmisión de significados culturales y relacionar las culturas mapuche-occidental y, que al mismo tiempo estimule el crecimiento del profesor no indígena (Durán et al, 2000). Una de las tareas fundamentales que se atribuye a estos educadores es mostrar las expresiones de la manera más auténtica posible a fin de respetar las normas propias de contextualización del habla, es decir tal como ocurren en la cultura.

Se trata de reconocer y considerar en la enseñanza la estrecha relación entre lengua y cultura, pues es por medio de la lengua que los sujetos adquieren los patrones culturales de pensamiento y de conducta de su comunidad.

\section{El contexto de la experiencia}

La experiencia educativa se realizó en la Región del Biobío, espacio territorial localizado en el margen norte de la tradicional Araucanía, específicamente en áreas geográficas al interior de ella caracterizadas por concentrar dos identidades culturales-territoriales mapuche: lafkenche en la zona costera (Arauco) y pewenche en la zona precordillerana (Alto Biobío).

Desde la perspectiva sociolingüística, estas identidades culturales-territoriales presentan realidades diferenciadas. En la primera, se ha evidenciado el retroceso significativo de la lengua originaria (Gundermann et al., 2008), como parte de un proceso histórico de larga data asociado a la ocupación del territorio por el Estado chileno, en el siglo XIX, y a la influencia castellanizadora de la escuela pública en el siglo XX. Los jóvenes poco y nada hablan la lengua indígena, quedando relegado a los mayores (adultos) el conocimiento y el hablar de la lengua originaria.

Por su parte, la identidad pewenche se caracteriza por su vitalidad lingüística presentándose un dominio generalizado de la lengua en todas las edades (Gundermann et al., 2008, Henríquez, 2014). Por su lejanía de los centros poblados del país y el difícil acceso a sus espacios de poblamiento (valles occidentales de la Cordillera de los Andes), la cultura y la lengua se han mantenido con baja intervención de componentes exógenos, aunque recientes testimonios de contexto visualizan una cierta declinación entre los jóvenes a propósito de la incorporación de los medios de comunicación de cuño occidental.

Desde estos antecedentes sociolingüísticos es que se diseñó la propuesta educativa, en el marco de un proyecto de fortalecimiento lingüístico patrocinado por la Corporación de Desarrollo Indígena (CONADI). Esta institución estatal, creada por la Ley Indígena (1993), tiene como uno de sus objetivos estratégicos el "incrementar el aprendizaje de las lenguas 
y las culturas originarias en niños y jóvenes indigenas, a través de la educación formal y la práctica de enseñanza tradicional, para fomentar la identidad de los pueblos indigenas"1. En este propósito es que la institución proyectó una alianza con académicos universitarios, que pudieran favorecer el logro de su objetivo estratégico de carácter educativo-lingüístico.

Los jardines infantiles (denominación que reciben en Chile los centros educativos preescolares) interculturales (aquellos que poseen un alto componente escolar indígena) que comprometieron su participación en el proyecto fueron seis, todos ellos ubicados en áreas de alta concentración de población indígena en contexto mapuche y que atienden a escolares que provienen de las identidades territoriales mapuche-lafkenche y mapuche-pewuenche. Ambas se localizan en la Región del Biobío, Chile. Información más específica de los centros se muestran en la siguiente tabla:

Tabla $N^{\circ} 1$

\begin{tabular}{|c|c|c|c|c|}
\hline Nombre Jardín & No de párvulos $^{\text {Comuna }}$ & Provincia & Identidad de referencia \\
\hline RalcoLepoy & 8 & Alto Biobío & Bio-Bío & Mapuche-pehuenche \\
\hline Ranquilhue & 14 & Tirúa & Arauco & Mapuche-lafkenche \\
\hline Calebu & 15 & Contulmo & Arauco & Mapuche-lafkenche \\
\hline Antiquina & 18 & Cañete & Arauco & Mapuche-lafkenche \\
\hline Huentelolén & 15 & Cañete & Arauco & Mapuche-lafkenche \\
\hline Pangue & 15 & Los Álamos & Arauco & Mapuche-lafkenche \\
\hline
\end{tabular}

FUENTE: elaboración de los autores

En términos de administración educativa estos centros son controlados por dos instituciones distintas: unos están bajo la dependencia de la Fundación INTEGRA y otros de la JUNJI (Junta Nacional de Jardines Infantiles) quien a su vez ha delegado su administración financiera en los municipios en que se ubica el centro. ${ }^{2}$

Respecto de la composición étnica del estudiantado, la totalidad de los escolares que asisten a los jardines interculturales se adscribe a la etnia mapuche, si se considera los criterios establecidos en la Ley Indígena (hijos de padre o madre indígena y/o que posean a lo menos un apellido indígena), pero no todos ellos provienen de familias con identificación étnica. La identidad étnica, entendida como conciencia de pertenencia a un grupo cultural y desde la cual se configuran prácticas y relaciones socioculturales interétnicas, es posible visualizarla con mayor intensidad en el espacio pewenche, presentándose mayormente diluida en el espacio territorial lafkenche, al igual que el habla originaria (CONADI, 2011).

\footnotetext{
${ }^{1}$ Funciones que pueden leerse en su página institucional, http://www.conadi.gob.cl. Esta institución, de manera autónoma y/o en paralelo al Ministerio de Educación, se encarga de desarrollar programas de fortalecimiento de la lengua indígena en el país.

${ }^{2}$ Los centros educativos de Ralco Lepoy, Ranquilhue y Pangue, pertenecen jurisdiccionalmente a la JUNJI; Calebu, Antiquina y Huentelolén, pertenecen a la Fundación INTEGRA.
} 


\section{Bases pedagógicas de la propuesta}

El diseño de la propuesta educativa en sus líneas preliminares fue esbozado por los docentes que contaban con experiencia en el trabajo educativo en indigeneidad. ${ }^{3}$ Dos presupuestos epistémicos constituyeron la base de la propuesta pedagógica: la construcción cooperativa y dialógica del conocimiento y la valoración de los saberes que portaban los diversos agentes educadores involucrados en el proyecto. El primero se tradujo en el fomento de la participación comunitaria en la gestión educativa y en la selección de los saberes culturales que darían vida al proceso de enseñanza-aprendizaje (organización del currículum). Desde este principio se pretende romper con el carácter exógeno e impositivo de la "asistencia técnica" que se configura e implementa-generalmente- desde la academia, en donde los colectivos que viven la desigualdad y a quienes se pretende favorecer, sus voces no son consideradas dentro de la ejecución de la propuesta de mejoramiento.

La propuesta está en línea con aquellas experiencias educativas internacionales caracterizadas como exitosas en su actuación en contextos de desigualdad y exclusión educativa, como las implementadas en Estados Unidos (escuelas aceleradas, programa de desarrollo escolar, programa éxito para todos/as), en España y Brasil (comunidades de aprendizajes); y aquella que se viene implementado en Chile, a través del Proyecto Enlazando Mundos. ${ }^{4}$ En ellas queda en evidencia la necesidad de modificar radicalmente el trabajo pedagógico del profesorado en su contexto de actuación, en el sentido de involucrar otros agentes educadores al interior del aula, a manera de soporte y apoyo pedagógico para las y los educadores, lo que en principio asegura un aumento de las interacciones sociales a que se expone el alumnado, lo que favorece la adquisición y ampliación de la lengua materna y -en general- su horizonte lingüístico (Ferrada y Flecha, 2008).

En este propósito, se realizaron dos encuentros iniciales que convocaron a todos los actores educativos en los que se definió la estrategia global de enseñanza -que permitiría alcanzar logros de aprendizaje en la lengua y la cultura- y la construcción del procedimiento evaluativo que daría cuenta de los logros de aprendizaje de la lengua. A partir de aquello, se programaron reuniones mensuales en que se discutió el avance y las dificultades que se observaron en el desarrollo de la experiencia educativa.

Los saberes que se seleccionaron y en torno a los cuales se organizó el currículum, fueron los siguientes:

- El mapudungun en la comunicación diaria (los saludos y breves diálogos).

- El hogar y sus utensilios

- Los recursos alimenticios (de la tierra, del mar, de la recolección)

- Los animales y aves domésticas y silvestres

- La familia y el sistema de parentesco

- Religiosidad y practicas culturales (rogativas, ceremonias y juegos)

- Vestimenta, adornos e instrumentos musicales

- El Wallmapu (medio natural y los astros)

- El cuerpo humano

\footnotetext{
${ }^{3}$ Los autores de este artículo.

${ }^{4}$ Enlazador de Mundos es un grupo de investigación e intervención para la promoción de la igualdad educativa, que convoca a agentes y agencias de diversas proveniencias.
} 
El otro presupuesto, involucró considerar como valioso y legítimo el saber cultural aportado por los/as educadores/as tradicionales indígenas (ELCI y asesor lingüístico indígena), también el saber acumulado en las experiencias de las educadoras no indígenas que actúan en el contexto intercultural (educadoras de párvulos occidentales y supervisoras institucionales); y en el mismo nivel, el conocimiento pedagógico aportado por los académicos universitarios. La racionalidad que movilizó este diálogo de saberes se fundamenta en un entendimiento de lo curricular como un proceso de construcción social en donde los diversos conocimientos interactúan en el marco de relaciones sociales de aprendizaje, ayuda y cooperación.

La estrategia educativa definida tuvo como expresión central la presencia en el aula preescolar de educadoras y educadores de la lengua y cultura indígena (ELCI), quienes implementaron estrategias de enseñanza de la lengua mapuche diseñadas en conjunto con la educadora de párvulos no indígena. Estas estrategias tenían como eje central el uso del mapuzugun como base de la comunicación, evitando la utilización traductiva de la lengua, en los momentos en que intervenían las y los educadores tradicionales. De acuerdo con la lógica formativa mapuche, el medio natural se constituyó en un espacio propicio para el desarrollo de estrategias de enseñanza, nominando la diversidad de objetos y recursos que en él se encuentran.

El trabajo de las/los ELCI fue apoyado por el asesor lingüístico indígena -quien formaba parte del equipo técnico universitario- el que aportaba en el ámbito del contenido semántico del habla mapuche (significado de palabras y expresiones) y, también en la provisión de ideas y recursos didácticos para la enseñanza de la lengua (presentación de relatos-epew, juegos, cantos, entre otros). Las educadoras no indígenas, por su parte fueron apoyadas en la programación curricular de aula por los docentes universitarios.

En definitiva la propuesta pedagógica se organizó e implementó en base a los siguientes criterios:

- Una organización de contenidos de aprendizaje que da cuenta de prácticas sociales, de componentes culturales y naturales propios de la realidad inmediata de los aprendices;

- La implementación de estrategias de enseñanza que recogen formas de enseñar y de aprender propias de la lógica formativa mapuche, como el aprender a observar y aprender a escuchar, en el que la lengua mapuzugun actúa como base de las estrategias diseñadas: relatos educativos mapuche (epew), exploración del medio natural, participación en ceremonias propias de la cultura, entre otras;

- Diseño de experiencias de aprendizaje contextualizada a las identidades territoriales mapuche, considerando la existencia de variaciones lingüísticas y de diversidad natural entre ellas;

- Promoción de relaciones educativas dialógicas y cooperativas en el centro educativo y con las familias y comunidad en que está inserta el centro educativo, en el entendido que la primera fuente de aprendizaje de la lengua proviene del hogar.

Respecto de la participación de las familias y comunidad, se parte de la premisa que si bien el trabajo pedagógico en los centros educativos resulta relevante para el aprendizaje de la lengua originaria, sus alcances resultan limitados sin la incorporación de la familia y 
la comunidad en la propuesta. Para ello se realizaron jornadas de sensibilización en todos los centros educativos partes del proyecto y se comprometió el apoyo en el habla del mapuzugun desde los hogares, así como la presencia de miembros de la comunidad hablantes en actividades educativas de los jardines, para narrar historias locales y la realización de ceremonias en que se expresa de manera natural la lengua mapuzugun.

En definitiva, el eje central de la propuesta descansó en un trabajo de construcción colectiva de los sentidos y procedimientos específicos para lograr el propósito central del proyecto, es decir todos los agentes educativos participando con ideas y acciones en la tarea de fortalecer el habla originaria entre los párvulos y también en su comunidad circundante. Asociado al aprendizaje de la lengua por los infantes indígenas se encuentra la proyección cultural e identitaria del mundo mapuche y es por ello que cualquier propuesta de fortalecimiento de la lengua -a nuestro entender- debe considerar necesariamente la participación de la comunidad en su desarrollo.

\section{Resultados}

En el momento en que se organizó el currículum también se procedió a diseñar el procedimiento y el respectivo instrumento evaluativo que daría cuenta del estado inicial del habla mapuzugun y de los logros en el aprendizaje con la implementación de la propuesta educativa.

Como procedimiento, se definió recoger información acerca del estado inicial de dominio lingüístico que portaban los infantes mapuche al momento de la implementación del proyecto, en la modalidad pre-test, para luego contrastarla con una segunda recogida de información al finalizar la propuesta, modalidad pos-test, que permitiría por un lado visualizar las trayectoria de aprendizajes de los preescolares y por otro retroalimentar la propuesta pedagógica diseñada.

Para ello se construyó un instrumento de medición del dominio de la lengua que diera satisfacción en su escritura a las exigencias de una lengua tradicionalmente basada en la oralidad y, por otra parte que integrara en su estructura las variaciones lingüísticas contextuales, propias de una lengua que se desarrolla en la interacción cotidiana y en estrecha relación con el medio natural y social. El instrumento consistió en una plantilla escrita compuesta por un conjunto de palabras que se representaban por sus respectivas láminas o imágenes.

Naturalmente, en el proceso de construcción de este instrumento las y los ELCI y el asesor lingüístico desempeñaron un rol fundamental en acordar y definir el vocabulario base del instrumento, así como las variaciones aceptadas.

El instrumento quedó integrado por 102 palabras y expresiones asociadas a los distintos ámbitos y saberes organizados en el currículum. Estos ámbitos se expresan en el cuadro siguiente: 
Tabla $N^{\circ} 2$

\begin{tabular}{|c|c|}
\hline Ámbitos & $\mathbf{N}^{\mathbf{0}}$ de palabras y expresiones \\
\hline Animales domésticos & 12 \\
\hline Animales y aves del campo & 10 \\
\hline Utensilios y materiales de la cocina & 14 \\
\hline Alimentos & 16 \\
\hline Partes del cuerpo humano & 18 \\
\hline Practicas culturales & 7 \\
\hline Instrumentos musicales & 7 \\
\hline Integrantes de la familia & 6 \\
\hline Wallmapu (astros y medio natural) & 11 \\
\hline
\end{tabular}

FUENTE: elaboración de los autores

Definido el vocabulario base del instrumento, se procedió a elaborar láminas que representaban la imagen asociada a la palabra. Se construyó así un set de imágenes con sus respectivas pautas que fue entregado a cada uno los seis centros educativos, según el número de infantes matriculados. También se entregó un protocolo de aplicación del instrumento que las educadoras debían administrar en conjunto con las y los ELCI.

El instrumento se aplicó a cada uno de los niños y niñas de los centros y las respuestas se vaciaron en una plantilla que agrupaba estas respuestas según su dominio o no dominio.

\subsection{La aplicación de entrada (pre-test)}

Los resultados de la aplicación primera del instrumento (modalidad pre-test) se presentan en el siguiente gráfico:

\section{Gráfico $N^{\circ} 1$}

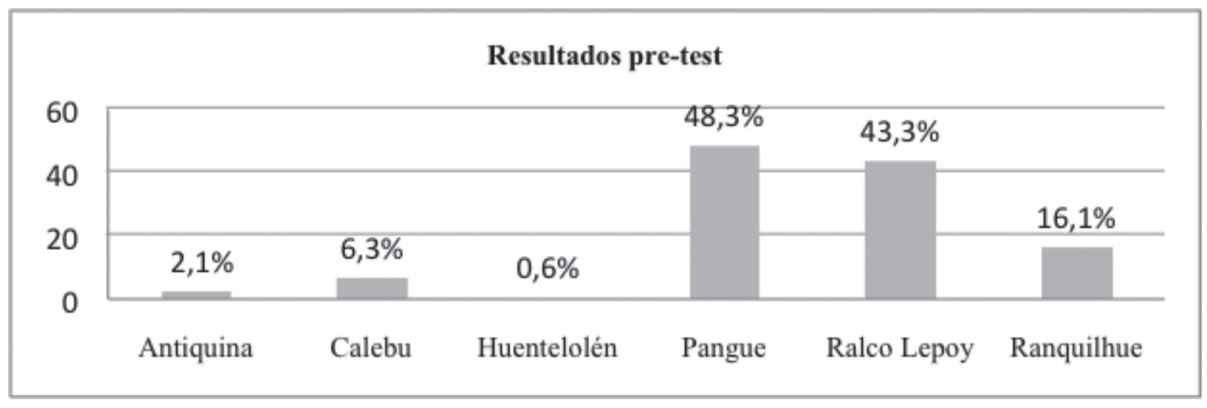

FUENTE: elaboración de los autores 
Una primera lectura nos permite visualizar el desnivel en el dominio de la lengua entre los diversos centros, en el que claramente los centros de Pangue y Ralco Lepoy destacan por su elevado resultado en relación con los otros jardines. El caso de Pangue es interesante, pues es un centro educativo mapuche lafkenche situado en un espacio geográfico con creciente urbanización y en donde la información previa disponible indicaba que el número de hablantes era muy reducido. Sin embargo, también teníamos información que el centro -en los dos años anteriores- había sido apoyado por una educadora tradicional indígena de amplio reconocimiento en la comunidad y por parte de las educadoras no indígenas. El mérito fundamental que se reconocía en esta educadora era su capacidad para lograr aprendizajes en los infantes e involucrar a la comunidad en actividades propias de la cultura que reportaban un conocimiento de la lengua, inclusive para los adultos.

Respecto del Jardín Ralco Lepoy, su resultado era esperable considerando las características del medio mapuche pewenche previamente descritas.

El nivel de conocimiento de la lengua mapuzugun evidenciado por los otros jardines dan cuenta de la preocupante situación de retroceso del habla indígena en las nuevas generaciones, lo que hacía más pertinente el proyecto y el desafío de revalorizar la lengua y la cultura en el preescolar indígena. Estos tres centros con los más bajos resultados son los que dependen de la Fundación INTEGRA, organismo que no había incorporado una impronta intercultural en su trabajo educativo en contexto mapuche, como si lo había hecho JUNJI.

\subsection{La aplicación de salida (pos-test)}

En un tiempo de seis meses desde la implementación de la propuesta pedagógica se aplicó por segunda vez el instrumento de evaluación, esta vez con el propósito de conocer el estado de avance o porcentaje de logro en el dominio de la lengua mapuzugun.

Los resultados se expresan en el siguiente gráfico

Gráfico $N^{\circ} 2$

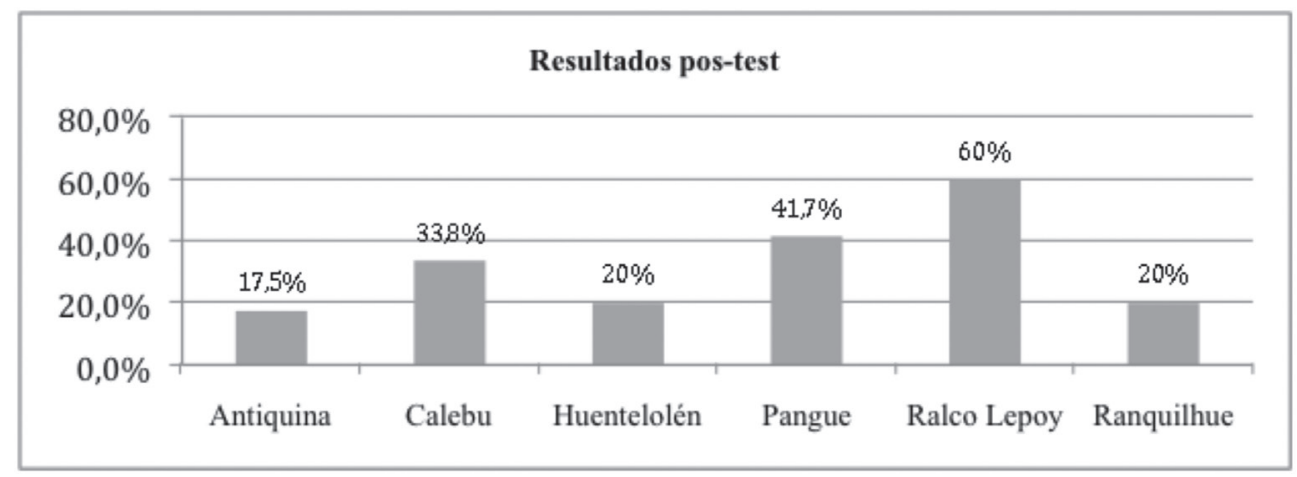

FUENTE: elaboración de los autores

La generalidad de los centros elevó sus resultados de aprendizaje, algunos de manera significativa, como el centro de Calebu con un $28 \%$ de crecimiento. 
Llama la atención que los tres centros con más bajos resultados en el pre-test muestran niveles de avance en el aprendizaje de la lengua y son los que porcentualmente mayores logros alcanzaron.

La excepción en el aumento de los resultados de aprendizaje es el jardín de Pangue, tal vez explicable por ciertos inconvenientes en su funcionamiento (problemas en el abastecimiento de agua) que impidieron la realización de clases, así como el cambio de la planta de educadoras mientras se ejecutaba el proyecto. A pesar de ello, mantienen un logro de aprendizaje superior a otros cuatro jardines.

El jardín Ralco Lepoy es el que muestra mayores resultados en el dominio de la lengua indígena, y tiene un aumento satisfactorio en relación con la medición inicial.

\subsection{Vinculación entre el centro educativo y la comunidad}

Tanto la construcción cooperativa y dialógica del conocimiento como la consideración de los saberes que portan los educadores tradicionales indígenas y los no indígenas, se constituyeron en ejes que dieron potencialidad a la propuesta, en tanto fuentes coordinadoras de las definiciones y acciones a implementar para el logro de los aprendizajes esperados. Sin embargo, un trabajo educativo realizado desde este enfoque viene a romper con las estructuras tradicionales de trabajo escolar, lo que generó una inicial resistencia en sujetos educadores que no estaban dispuestos a tranzar sus prácticas y creencias acerca de lo "propiamente" educativo.

Con todo, las evaluaciones realizadas desde la institucionalidad (CONADI y centros educativos) y de las comunidades indígenas, coinciden en plantear la vinculación y reconocimiento que se produjo entre los centros educativos y la comunidad originaria, cuestión que redundó en aprendizajes para los infantes mapuches, pero también para los educadores, en tanto se avanzó en superar visiones pedagógicas monoculturalistas por un enfoque comunicativo e intercultural.

\section{Discusión}

En primer lugar, cabe destacar el rol estratégico que adquiere la escuela en la configuración de la política lingüística del Estado, pues a través de sus prácticas educativas se instituyó el desuso e ilegitimidad de las lenguas indígenas, pero a la vez parece tener la potencialidad para revitalizarlas según las definiciones curriculares que se adopten en las comunidades educativas. Para ello, adquiere importancia una resignificación de lo pedagógico-curricular, en tanto implique avanzar desde un entendimiento técnico instrumental de los saberes y de la acción educativa del sistema escolar hacia construcciones curriculares que involucren la diversidad de saberes y de sujetos que están presentes en estos espacios educativos. Siendo esto válido para todo el sistema escolar, en centros educativos que buscan revitalizar la lengua indígena el diálogo de saberes se constituye en el eje vertebrador en el diseño de las situaciones de aprendizaje, en tanto el principal agente educador es aquel que posee el conocimiento de la lengua y la cultura y por ello se encuentra habilitado para definir los saberes y formas de enseñar. Desde esta perspectiva, se avanza en una comprensión de lo pedagógico curricular como una construcción social y culturalmente contextualizada, que 
no puede ser concebida sin los actores involucrados en el proceso educativo y, menos aún, determinada desde agencias exógenas.

Lo anterior supone partir de la premisa que la actuación de las y los educadores en espacios culturales indígenas se asienta en una práctica educativa ajustada al contexto de desempeño, en donde los saberes culturales originarios y sus lógicas formativas forman parte del sistema escolar. Actuaciones docentes de esta naturaleza requieren su correlato en la formación inicial de modo que ésta asuma los procesos formativos desde la complejidad del trabajo pedagógico en indigeneidad (Turra et al., 2013), y para ello el trabajo en redes que vinculen al menos tres actores institucionales claves como son escuela, universidad y comunidad, resulta fundamental para un entendimiento del quehacer docente desde un trabajo colaborativo y comunitario, base de cualquier proceso de movilización educativa (Turra, 2012).

Respecto de los resultados en el aprendizaje de la lengua, las evidencias muestran un aumento en el dominio lingüístico en relación a los saberes en torno a los cuales se organizó el currículo de los centros preescolares. Sin embargo, no se puede caer en la tentación de atribuir a los aspectos didácticos de la propuesta la responsabilidad última de estos logros, por lo demás de alcance temporal reducido. Tenemos claridad que las posibilidades de movilización educativa y avance en la revitalización de la lengua indígena no recae solo en lo que los agentes educadores realicen desde las aulas escolares, sino en cómo se produce sinergia entre el sistema educativo y las comunidades originarias para producir una actitud lingüística que valorice el uso y dominio de la lengua originaria, tanto en la comunicación cotidiana como en su inserción curricular.

Desde esta línea de argumentación, se puede plantear que los avances en el dominio de la lengua originaria se encuentran en directa relación con los complejos culturales mapuche de que se trate (lafkenche o pewenche); esto es, como se expresa en la contextualización de la propuesta, las realidades lingüísticas son distintas en los diversos ambientes territoriales y culturales del mundo mapuche, por lo tanto los logros de aprendizaje deben evaluarse en función de su estado inicial. Ciertamente, los niños y niñas que asisten al centro educativo de Ralco Lepoy (comunidad pewenche) presentan un mayor dominio de la lengua que los infantes mapuche-lafkenche, realidad que se asocia a la importancia y utilidad de la lengua vernácula en la interacción cotidiana, situación que favorece el estado de habla del mapudungun y que debe considerar cualquier propuesta educativa de fortalecimiento del habla indígena. El objetivo aquí es proyectar el habla indígena materna en el centro educativo, en conjunto con el castellano, lengua que en muchos casos estos niños y niñas aprenden en el sistema escolar, para de este modo otorgar proyección y legitimidad al hablar mapuche.

Por su parte, los propósitos educativos dirigidos a comunidades lafkenches adquieren una dimensión distinta, pues aquí el retroceso de la lengua indígena lleva a que ésta actúe como segunda lengua. Los niños y niñas aprenden, salvo excepciones, el castellano en el hogar y en los centros educativos se inician en el mapudungun, por tanto aquí el objetivo es promover una acción conjunta entre el centro educativo y la comunidad de hablantes para que la lengua indígena sea hablada tanto en las interacciones cotidianas como en los procesos pedagógicos desarrollados en el centro educativo. Sin duda que en este proceso la presencia de las y los educadores/as tradicionales indígenas adquiere un rol fundamental para enseñar la lengua y cultura indígena. Además de constituirse en un referente de aprendizaje que encarna la cultura de base del estudiantado, es el agente que expresa las expectativas y necesidades de la comunidad para con el centro educativo. Desde su actuación educativa es de esperar que otros agentes sociales de la comunidad sean convocados a participar en 
actividades que impliquen desarrollar interacciones comunicativas que expresen de manera auténtica las normas de habla en la comunidad.

\section{Conclusiones}

Desde los sentidos de la experiencia educativa descrita, cabe postular que cualquier propuesta educativa que pretenda revitalizar el habla de la lengua indígena debe partir por considerar e involucrar a los hablantes de la comunidad como educadores de primera infancia y promover actuaciones educativas que generen comprensión, respecto de la importancia y utilidad de la lengua en la conformación de identidad y en el acceso al conocimiento de la cultura originaria. La comunidad es la primera formadora en la lengua, para luego continuar el proceso en el sistema escolar desde miradas integradoras de los agentes educadores comunitarios.

El diálogo de saberes como principio educativo y una comprensión sociocultural del currículo, que se construye en base a interacciones sociales de ayuda y cooperación, posibilita que las comunidades participen de sus propios procesos de movilización educativa y con ello romper con las propuestas exógenas que definen los alcances y orientaciones del cambio educativo que se necesita. De seguro, una propuesta de mejoramiento educativo generada desde procesos participativos conlleva una mayor potencialidad y proyección en el logro de sus objetivos, cuestión de evidente relevancia cuando se pretende generar igualdad educativa.

Finalmente, como se propone en esta experiencia educativa, se hace necesario superar una concepción instrumental de los programas de enseñanza de la lengua originaria, que subordina la lógica formativa mapuche al sistema escolar al igual que el desempeño de los educadores tradicionales, para avanzar hacia una comprensión dialógica e intersubjetiva del proceso formativo en la lengua, que autorice al centro educativo y a los docentes a involucrar una diversidad de agentes educadores en las labores de construcción curricular como en las de aprendizaje propiamente tal.

\section{Bibliografía}

Álvarez-Santullano, P. y Forno, A. (2008). "La inserción de la lengua mapuche en el currículum de escuelas con educación intercultural: un problema más que metodológico", en Alpha, 26: 9-28.

Aubert, A., Flecha, A., García, C., Flecha, R. y Racionero, S. (2010). Aprendizaje dialógico en la Sociedad de la Información. Barcelona: Hipatia.

Baronnet, B. (2013). "Lenguas y participación comunitaria en la educación indígena en México", en Revista de Antropología Iberoamericana, 8, 2:183-208.

Catrileo, M. (2005). "Revitalización de la lengua mapuche en Chile", en Documentos Lingüísticos y Literarios, 28: 10-17.

En:www.humanidades.uach.cl/documentos_linguisticos/document.php?id=86 (consultado 14 Noviembre, 2013)

CONADI (2011). Diagnóstico del desarrollo cultural del pueblo mapuche. Región de la Araucanía. Santiago: Consejo Nacional de la Cultura y las Artes. 
Donoso, A. (2008). Educación y nación al sur de la frontera. Organizaciones mapuche en el umbral de nuestra contemporaneidad, 1880-1930. Santiago: Pehuén Editores.

Durán, T., Hernández, A. y Quidel, J. (2000). "Los educadores comunitarios mapuche y su contribución al Proyecto EIB", en Seminario Internacional sobre La Participación Comunitaria Indígena en la Educación Intercultural Bilingüe. Chile, Villarrica. (Inédito).

Ferrada, D. (2012). Construyendo escuela compartiendo esperanzas. Santiago: RIL Editores.

Ferrada, D. y Flecha, R. (2008) "El modelo dialógico de la pedagogía: Un aporte desde las experiencias de comunidades de aprendizaje”, en Estudios Pedagógicos, 34, 1: 41- 61.

Gundermann, H., Canihuan, J., Clavería, A. y Faúndez, C. (2008). Perfil sociolingüístico de comunidades mapuches de la Región del Biobio, Araucanía, los Ríos y los Lagos. Informe de Investigación. Santiago: CONADI - UTEM.

Gundermann, H., Vergara, J. y González, H. (2009). "El proceso de desplazamiento de la lengua aymara en Chile", en Cuadernos Interculturales, 12: 47-77.

Henríquez, M. (2014). "Estado del mapudungun en comunidades pewenches y lafkenches de la región del Bio-Bío" en RLA, 52, 2:13-40.

Martínez, F. (2004). Primera infancia, bilingüismo y educación infantil. Laguna de DueroValladolid: Editorial de la Infancia.

Mc Ewan, P. (2004). "La brecha de puntajes obtenidos en las pruebas por los niños indígenas en Sudamérica", en D. Winkler, D. y S. Cueto (eds.), Etnicidad, Raza, Género y Educación en América Latina. Santiago: PREAL, 283-313.

Quilaqueo, D. y Merino, M. (2003). "Estereotipos y prejuicio étnico hacia los mapuches en textos complementarios a la asignatura de Historia", en Revista Campo Abierto, 23: 119-135.

Quilaqueo, D., Merino, M. y Saiz, J. (2007). "Representación social mapuche e imaginario social no mapuche de la discriminación percibida", en Atenea, 496: 81-103.

Quintriqueo, S. (2010). Implicancias de un modelo curricular monocultural en contexto mapuche. Temuco: Ediciones Universidad Católica de Temuco.

Sousa Santos, B. (2009). Epistemología del Sur. México: Siglo XXI Editores.

Teberosky, A. y Soler, M. (2003). Contextos de alfabetización inicial. Barcelona: Horsori.

Turra, O. (2008-2009). "De la ocupación a la aculturación. Escuela chilena y pueblo mapuche en los siglos XIX y XX", en Revista de Historia, 18-19: 213-222.

Turra, O. (2012). "Política educativa para indigeneidad, construcción curricular y formación del profesorado" en Revista ISEES, 11: 89-99.

Turra, O., Ferrada, D. y Villena, A. (2013). "La especificidad del contexto indígena como requerimiento para la formación inicial del profesorado" en Estudios Pedagógicos, 39, 2: 329-339.

Vergara, J. y Gundermann, H. (2005). Descripción del contexto sociolingüistico en comunidades indigenas de Chile. Santiago: MINEDUC-Programa EIB/Orígenes.

Wittig, Fernando. (2009). "Desplazamiento y vigencia del mapudungún en Chile: un análisis desde el discurso reflexivo de los hablantes urbanos" en $R L A$, 47: 135-155. 